\title{
Cirrose hepática e hemocromatose neonatal secundária associadas à tirosinemia tipo 1: relato de um caso e diagnóstico diferencial com hemocromatose primária hereditária
}

Liver cirrhosis and secondary neonatal haemochromatosis associated to type 1 tyrosinemia: case report and differential diagnosis with hereditary haemochromatosis

Ana Paula Camargo Martins'; Maria Carolina Pospissil2; Maria Cristina Figueroa²; Paloma Rincon²; Betina Werner³; Maria José Serapião ${ }^{4}$; Lúcia de Noronha ${ }^{5}$

unitermos
Tirosinemia
Hemocromatose
Cirrose

\section{resumo}

Uma paciente de 4 meses de idade foi encaminhada ao hospital por aumento de volume abdominal, cianose e febre há dois meses. Ao exame, apresentou hepatoesplenomegalia. Com os resultados laboratoriais constatou-se anemia hipocrômica microcítica, leucocitose, plaquetopenia e provas de função hepática alteradas. Levantou-se a hipótese de erros inatos do metabolismo. A paciente evoluiu desfavoravelmente e foi a óbito. À necropsia o fígado apresentou-se cirrótico e com grande depósito de ferro no parênquima. O diagnóstico anatomopatológico foi hemocromatose hereditária, no entanto os resultados laboratoriais confirmaram tirosinemia tipo 1. Tanto a hemocromatose primária quanto a tirosinemia evoluem com cirrose hepática, sendo que a segunda pode ocasionalmente levar ao depósito de ferro do tipo hemocromatose secundária, o que dificulta muito a diferenciação entre elas com bases puramente anatomopatológicas, acarretando, assim, um diagnóstico errôneo de hemocromatose hereditária. Esse diagnóstico diferencial muitas vezes só é possível com os achados de rastreamento de erros inatos do metabolismo.

A 4-month-old female patient was taken to hospital due to increase in abdominal volume, cyanosis and fever for two months. At examination, she presented hepatosplenomegaly. Laboratory tests revealed hypochromic anemia (due to iron deficiency), leucocytosis, low platelet count and altered hepatic functions. Innate metabolic error was suspected. Follow-up developed unfavorably and she died. At necropsy, the liver was cirrhotic, with large iron deposits in the parenchyma. Necropsy diagnosis was haemochromatosis, and laboratorial results confirmed type 1 tyrosinemia. Either primary haemochromatosis or tyrosinemia could cause hepatic cirrhosis. Tyrosinemia may also cause iron deposits in the liver parenchyma, similar to those observed in secondary haemochromatosis. Such facts can make differential diagnosis difficult between these and other conditions such as hereditary haemochromatosis. In fact, differential diagnosis is only achievable by using laboratorial tests for innate metabolic errors.

1. Bióloga do Laboratório de Patologia Experimental, da Pontificia Universidade Católica do Paraná (PUCPR); aluna de pós-graduação.

2. Acadêmica de Medicina da PUCPR.

3. Médica patologista; mestre em Medicina pela Universidade Federal do Paraná (UFPR).

4. Patologista pediátrica do Serviço de Anatomia Patológica do Hospital de Clínicas da Universidade Federal do Paraná (UFPR)

5. Professora do Curso de Pós-graduação em Ciências da Saúde da PUCPR. 


\section{Introdução}

A tirosinemia tipo 1 é uma doença metabólica e de herança autossômica recessiva causada pela deficiência de fumarilacetoacetato hidrolase, cujo gene está situado no cromossomo 15q 23-25. Essa enzima intervém no final da degradação da tirosina, determinando sua deficiência e acúmulo de fumarilacetoacetato e maleiacetoacetato, que vai derivar para succinilacetoacetato, succinilacetona e $\delta$-aminolevulínico, prejudiciais às células do organis$\mathrm{mo}^{(2-4,6,10,12,13)}$.

A história natural da tirosinemia tipo 1 é caracterizada por severo distúrbio hepático, renal e neurológico. Já foram descritas duas formas de apresentação clínica: uma agu$\mathrm{da}$, manifestada de forma grave entre o segundo e sexto mês de vida, e uma forma crônica que se apresenta com sintomas similares, porém de evolução mais lenta e tardia, geralmente, após seis meses de vida ${ }^{(13)}$.

Os exames laboratoriais mostram elevação das transaminases hepáticas e bilirrubina com déficit dos fatores de coagulação, fosfatúria, hipercalciúria, glicosúria, acidose metabólica. Exames específicos revelam aumento de alfafetoproteína, antes mesmo da alteração da concentração plasmática de tirosina e metionina. A presença de succinilacetona na urina é diagnóstica. A atividade da enzima fumarilacetoacetato pode ser medida na cultura de fibroblastos da pele ou hepatócitos para confirmação do diagnóstico ${ }^{(3)}$.

A hemocromatose hereditária $(\mathrm{HH})$, também classificada como uma doença de herança autossômica recessiva, caracteriza-se como doença primária por acúmulo de ferro, sendo mais comum em caucasianos do norte europeu ${ }^{(5,14,15)}$. Pessoas saudáveis normalmente absorvem $10 \%$ do ferro contido na dieta ingerida. Pessoas com HH absorvem cerca de $20 \%$ do ferro da dieta. O organismo não tem meios naturais de eliminar o ferro extra, ocasionando danos em vários órgãos, principalmente fígado, pâncreas, coração, articulações, pele e glândula pituitária ${ }^{(5,15)}$. A doença pode se manifestar desde as primeiras horas do nascimento, o que é mais comum, até poucas semanas de idade. Os pacientes mostram características de falência hepática, como hipoalbuminemia, hipoglicemia, coagulopatia, fibrinogênio baixo e, freqüentemente, trombocitopenia e anemia. A ascite e a hiperbilirrubinemia podem estar presentes ao nascimento ou se desenvolver logo após. As transaminases normalmente estão baixas ${ }^{(9)}$.

Pacientes com hemocromatose hereditária apresentam atividade aumentada da redutase férrica, aumento da expressão da proteína transportadora divalente de metal 1 (DMT 1), diminuição do armazenamento de ferritina nos enterócitos e aumento da expressão da ferroportina $1^{(9,14,15)}$.

A concentração de ferritina sérica está elevada em pacientes com hemocromatose, no entanto isso somente demonstra acúmulo de ferro no organismo, doença hepática não-específica ou inflamação. A capacidade de ligação do ferro (transferrina) está baixa, pois há dano hepático, sendo que a porcentagem de saturação do ferro está aumentada, o que, entretanto, não revela se a hemocromatose é primária ou secundária ${ }^{(9)}$.

\section{História clínica e exame físico}

Paciente do sexo feminino, 4 meses, há dois meses com aumento do volume abdominal associado a cianose e febre. Foi sugerido diagnóstico de anemia, sendo prescrito sulfato ferroso. Ao exame físico, sinais de sangramento nasal, abdome globoso, distendido, com fígado palpável a $4 \mathrm{~cm}$ do rebordo costal direito e baço palpável a $7 \mathrm{~cm}$ do rebordo costal esquerdo.

Os exames solicitados revelaram anemia hipocrômica microcítica, leucocitose, plaquetopenia e provas de função hepática alteradas. Através de exames laboratoriais e de imagem foram afastados outros diagnósticos diferenciais de hepatopatias em lactentes, como malformações, hepatites virais, citomegalovirose, entre outras doenças crônicas intra-uterinas que cursam com lesão hepática, neoplasias primárias e metastáticas e doenças vasculares. Foi, então, sugerido screening para erros inatos do metabolismo, principalmente para galactosemia e tirosinemia. A cromatografia de aminoácidos no plasma revelou excreção aumentada de tirosina (total de $10,5 \mathrm{mmol} / \mathrm{dl}$ para um padrão normal de até $3 \mathrm{mmol} / \mathrm{dl}$ ), excreção normal de fenilalanina (total de $2,1 \mathrm{mmol} / \mathrm{dl}$ para um padrão normal de até $4 \mathrm{mmol} / \mathrm{dl}$ ) e succinilacetona (total de $21,3 \mathrm{mmol} / \mathrm{dl}$ para um padrão normal entre 2 e $165 \mathrm{mmol} / \mathrm{dl}$ ), além de aumento da excreção de nitroso naftol (+++/IV). O screening para erros inatos do metabolismo realizado na irmã gêmea dizigótica da paciente foi normal. O screening para erros inatos revelou tratar-se de tirosinemia tipo I.

Iniciou-se então alimentação com fórmula TYR 1, modificada, porém a evolução foi insatisfatória. A paciente evoluiu com encefalopatia, episódios convulsivos, irregularidade respiratória, insuficiência renal, sangramento gastrointestinal e óbito. 
O exame anatomopatológico foi realizado sem o conhecimento do diagnóstico laboratorial de tirosinemia, sendo que foram omitidos propositalmente os resultados dos testes de triagem para erros inatos do metabolismo por se tratar de caso em estudo para reunião anatomoclínica departamental.

O exame interno revelou edema acentuado de tela subcutânea, leptomeninges com sufusões hemorrágicas disseminadas, derrame pleural à direita, ascite de $300 \mathrm{ml}$, bordo inferior de fígado $4 \mathrm{~cm}$ abaixo do rebordo costal direito, bordo inferior do baço em fossa ilíaca esquerda e petéquias disseminadas em serosas e mucosas. Tecido pulmonar difusamente congesto e edemaciado com hemorragia difusa. Estômago com várias úlceras puntiformes em antro e corpo. Duodeno apresentando mucosa com coloração ferruginosa. Fígado apresentando parênquima firme, esverdeado, difusamente nodular, e baço, congesto.

Ao exame microscópico observou-se pulmão com edema; membranas hialinas; hemorragia; atrofia tímica; dilatação tubular renal com proliferação discreta de matriz mesangial e glomerular; cirrose; colestase; acentuado depósito de ferro em células parenquimatosas do fígado, pâncreas, glândulas salivares, intestino, estômago e tireóide, confirmado pelo azul da Prússia (Figuras 1 e 2); aumento das ilhotas pancreáticas e atrofia acinar. Entre os órgãos sem acúmulo parenquimatoso de ferro estavam baço, timo, esôfago, intestino grosso, ovário, miocárdio, hipófise, rim, adrenal e pele.

Devido aos achados anatomopatológicos post mortem mostrarem um importante acúmulo de ferro em células parenquimatosas de vários órgãos, principalmente em fígado, pâncreas e tireóide, diagnosticou-se hemocromatose neonatal, sendo sugerida como causa primária a hemocromatose primária hereditária, entre outras doenças

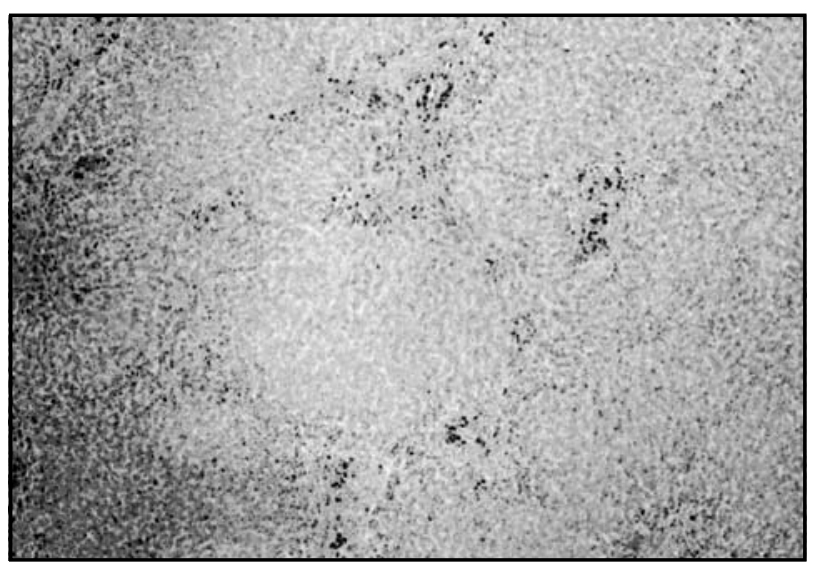

Figura 1 - Corte de fígado corado em azul da Prússia revelando depósito parenquimatoso de ferro acentuado além de cirrose $(4 x)$

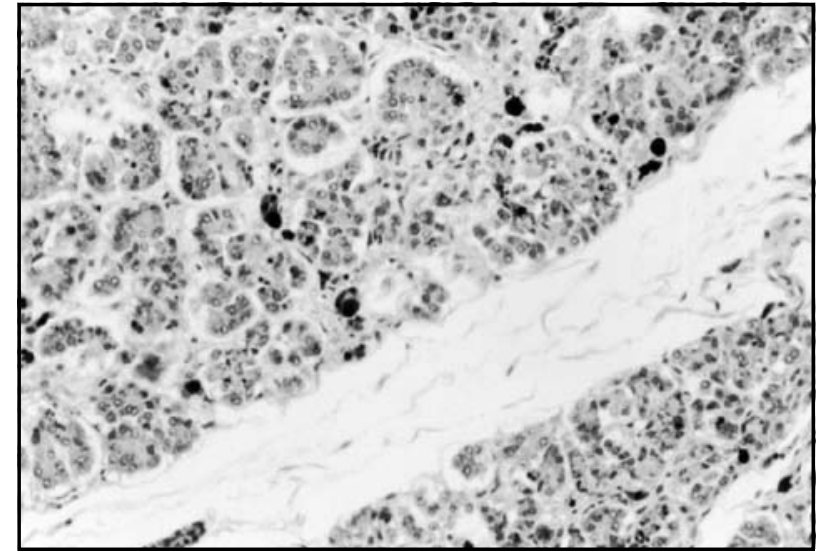

Figura 2 - Corte de pâncreas corado em azul da Prússia revelando depósito parenquimatoso de ferro (10x)

de acúmulo, principalmente pelo excessivo acúmulo de ferro no compartimento intraparenquimatoso. Em reunião anatomoclínica foi revelado o diagnóstico laboratorial de tirosinemia tipo 1.

\section{Discussão}

A hemocromatose neonatal é uma lesão caracterizada por falência hepática fulminante nos primeiros dias de vida na ausência de malformações congênitas. Cursa com hipoglicemia, coagulopatia, trombocitopenia, anemia e falência renal. Os níveis de alfafetoproteína são geralmente altos durante a gestação e a transferrina sérica geralmente é hipersaturada. Essa criança já apresentava evidentes sinais de falência hepática com apenas 4 meses de vida, evoluindo com anemia severa, coagulopatia e sangramentos, distúrbios metabólicos, encefalopatia hepática e falência renal. Não foram evidenciadas malformações. Nos exames laboratoriais foram observadas alterações compatíveis com tirosinemia tipo 1. As causas de hemocromatose neonatal incluem desde doenças infecciosas, principalmente virais, neoplasias primárias ou metastáticas, doenças vasculares, doenças de acúmulo, entre elas a tirosinemia, até desordens mitocondriais e hemocromatose primária hereditária. A hemocromatose neonatal idiopática é diagnosticada quando todas essas causas são descartadas ${ }^{(1,7)}$.

A hemocromatose primária hereditária e a tirosinemia podem evoluir com cirrose hepática e conseqüente elevação das transaminases, icterícia, ascite, hepatomegalia, coagulopatia, hipoglicemia, hipoalbuminemia, fibrinogênio baixo e anemia. O carcinoma hepatocelular pode ocorrer após o estabelecimento de cirrose em ambas as doenças. A lesão hepática carcinogênica na hemocromatose primária 
hereditária ocorre essencialmente devido ao acúmulo de ferro. Já na tirosinemia a lesão ocorre devido ao acúmulo de substâncias como o fumarilacetoacetato e o ácido aminolevulínico(3,4,11).

Na hemocromatose primária hereditária a biópsia do fígado apresenta grande depósito de ferro parenquimatoso intra-hepatocítico em áreas periportais. A hemossiderose em células de Kupffer apenas acontece em estágios mais avançados. Já a biópsia de fígado de pacientes com excesso de ferro secundário a outras doenças, como a tirosinemia, geralmente não mostra a característica de depósito férrico intra-hepatocítico periportal, isto é, padrão hemocromatóti$\mathrm{Co}^{(13)}$. Na grande maioria das vezes, os depósitos secundários de ferro são do tipo hemossideróticos, isto é, em células de Kupffer. Porém no caso apresentado foi encontrado acúmulo acentuado de ferro em células parenquimatosas do fígado cirrótico, além daquele visto em pâncreas, estômago, entre outros. Esse padrão de hemocromatose neonatal secundária é muito semelhante ao visto na hemocromatose primária hereditária e mais raro nas tirosinemias.

Nesse caso, além do depósito de ferro proporcionado pela própria fisiopatologia da doença, houve administração exógena de sulfato ferroso, levando, provavelmente, ao agravamento do depósito tecidual de ferro e, conseqüentemente, à evolução da doença ${ }^{(9,11,13)}$.

$\mathrm{Na}$ hemocromatose primária hereditária o excesso de ferro no organismo se faz pela deficiência que as células do sistema reticuloendotelial têm em acumular o metal. Essas células são responsáveis pela regulação da absorção duodenal de ferro e, em conseqüência à sua deficiência, haverá déficit na contra-regulação da absorção duodenal

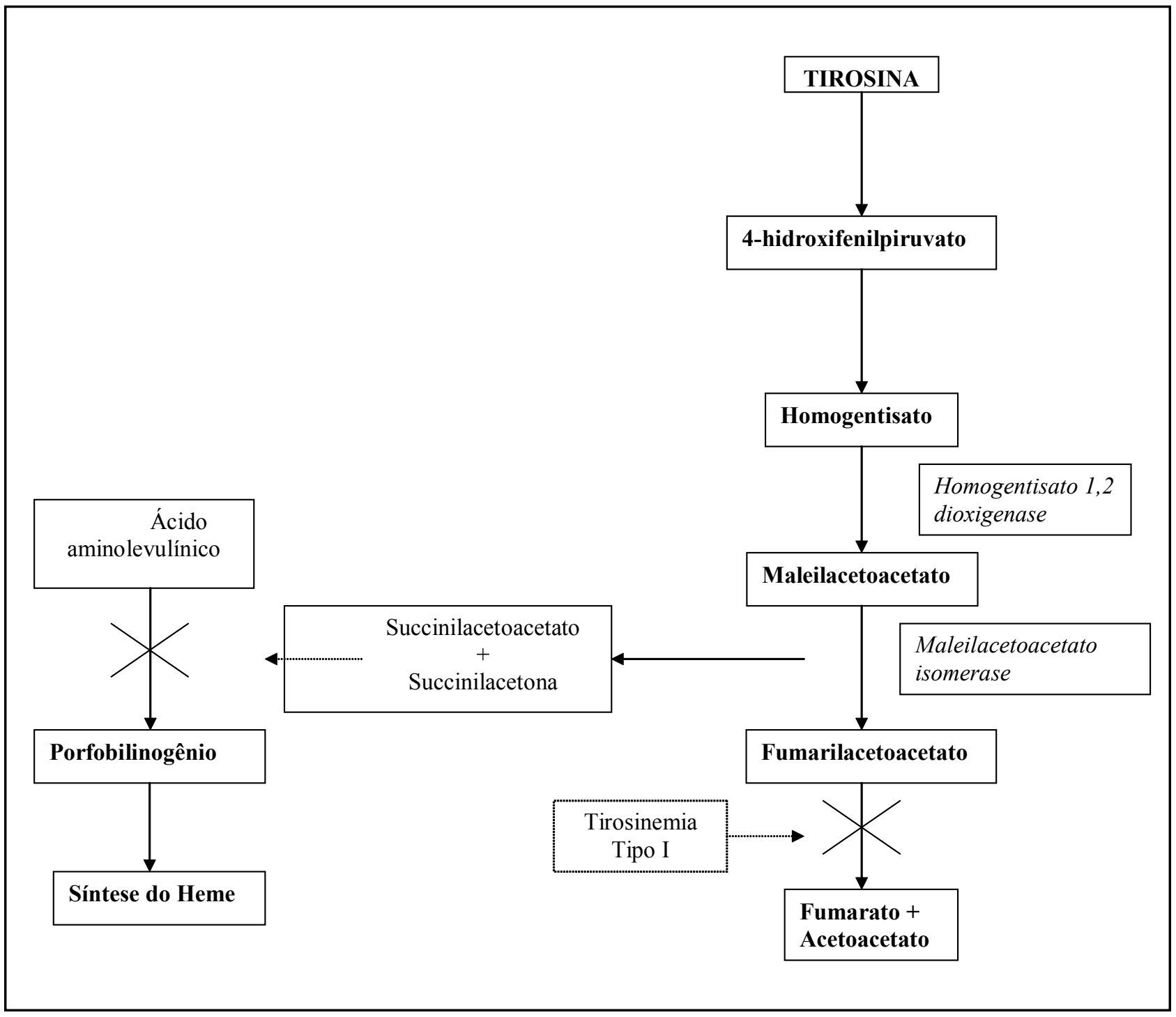

Figura 3 - Via bioquímica da degradação da tirosina 
de ferro e aumento na deposição desse metal nas células parenquimatosas do organismo, principalmente as hepáticas ${ }^{(8,11)}$. Acredita-se que essa regulação recíproca entre o sistema reticuloendotelial e a absorção intestinal de ferro seja realizada por um peptídio denominado hepcidina, que é sintetizado no fígado. Quando há aumento dos níveis férricos, também há aumento da hepcidina, e quando há diminuição ou deprivação de ferro, verifica-se uma diminuição desse peptídio. Assim sendo, quando há aumento do ferro sérico há acúmulo do mesmo nas células do sistema retículo endotelial e este, através da secreção de hepcidina, acarreta diminuição de sua absorção intestinal. Na hemocromatose hereditária não há feedback negativo sobre os enterócitos, pois não há fagocitose do ferro pelas células do sistema reticuloendotelial. Sendo assim, ocorre aumento na produção das proteínas regulatórias de ferro citosólico (IRP-1), que se ligando aos elementos ferro-responsivos (IRE), presentes no RNAm, vão aumentar a produção de transferrina e diminuir a de ferritina, simulando um falso estado de deprivação férrica e fazendo com que o organismo absorva cada vez mais ferro ${ }^{(8,11)}$.

$\mathrm{Na}$ tirosinemia, o excesso de succinilacetoacetato e succinilacetoacetona faz um bloqueio da enzima porfobilinogênio sintetase ocasionando a não-transformação do $\delta$-aminolevulínico em porfobilinogênio, com conseqüente acúmulo do primeiro (Figura 3). $O \delta$-aminolevulínico, entre outros efeitos, é capaz de ativar a IRP-1 com conseqüente aumento da ligação dessa proteína com IRE. Isso proporciona aumento na síntese da transferrina e diminuição de ferritina, ocasionando aumento na absorção de ferro intestinal e seu acúmulo no organismo. Porém não há deficiência das células do reticuloendotélio em acumular ferro; em vista disso, o acúmulo desse metal é geralmente mais acentuado nos histiócitos (hemossiderose) teciduais do que nas células parenquimatosas. Somente nas fases mais avançadas é que o depósito parenquimatoso começa a aparecer, como visto neste caso ${ }^{(8,11,13)}$. O inusitado aqui é que o depósito do tipo hemossiderótico é muito discreto, sendo a hemocromatose secundária muito mais acentuada. Esse fato acabou acarretando uma sugestão de diagnóstico anatomopatológico para hemocromatose primária hereditária. Porém a clínica e os achados laboratoriais em tudo levam a crer que se trata de um caso de tirosinemia tipo I com hemocromatose neonatal secundária. A concomitância das duas doenças até poderia ser considerada; entretanto, conforme já exposto, há uma explicação metabólica para que ocorra depósito secundário de ferro nos casos de tirosinemia.

\section{Conclusão}

A tirosinemia tipo 1 pode ocasionalmente levar ao depósito de ferro do tipo hemocromatose neonatal secundária, principalmente em fases avançadas da doença, dificultando muito o diagnóstico diferencial com hemocromatose primária hereditária utilizando bases puramente anatomopatológicas. Esse diagnóstico diferencial muitas vezes só é possível com os achados de rastreamento de erros inatos do metabolismo. Nas fases precoces, pré-cirróticas da hemocromatose primária hereditária o acúmulo parenquimatoso intra-hepatocítico de ferro parece ser mais acentuado na zona periportal. Já nas fases precoces da tirosinemia tipo 1 o acúmulo de ferro é mais do tipo hemossiderótico.

\section{Referências}

I. ANDREWS, N. C.; ANUPINDI, S.; BADIZADEGAN, K. Case 21-2005: a 4-week-old male infant with jaundice and thrombocytopenia. NEJM, v. 353, n. 2, p. I89, 2005.

2. CROFFIE, J. M. et al. Tyrosinemia type I should be suspected in infants with severe coagulopathy even in the absence of other signs of liver failure. Pediatrics, v. I03, n. 3, p. 675-9, 1999.

3. ENDO, F. et al. Animal models reveal pathophysiologies of tyrosinemia I, 2.J Nutr, v. I33, n. 6, p. 2063-7, 2003.

4. GROMPE, M. The pathophysiology and treatment of hereditary tyrosinemia type I. Sem Liver Dis, v. 2 I, n. 4, p. 563-72, 200 I.
5. National Digestive Diseases Information Clearinghouse Hemochromatosis [Pamphlet]. Disponível em:http://digestive. niddk.nih.gov/ddiseases/pubs/hemochromatosis/.

6. HEYER, E. One founder/one gene hypothesis in a new expanding population: Saguenay (Quebec, Canada). Human Biology, v. 7I, n. I, p. 99-110, 1999

7. JACKSON, R.; ROBERTS, E. A. Identification of neonatal liver failure and perinatal hemochromatosis in Canada. Paediatr Child Health, v. 6, n. 5, p. 248, 2001 .

8. KNUTSON, M. et al. Iron metabolism in the reticuloendothelial system. Crit Rev Biochem Mol Biol, v. 38, n. I, p. 6I-89, 2003. 
9. MURRAY, K. F. et al. Neonatal hemochromatosis. Pediatrics, v. 108 n. 4, p. 960-4, 2001.

I0. NARDIELLO,A. N. et al.Tirosinemia tipo l: reporte de un caso. Rev Chil Pediatr, v. 73, n. 6, p. 590-4, 2002.

1।. ONUKI, J. et al. Danos ao DNA promovidos por ácido 5-aminolevulínico: possível associação com o desenvolvimento de carcinoma hepatocelular em portadores de porfiria aguda intermitente. Quim Nova, v. 25, n. 4, p. 594-608, 2002
12. SIEGFRIED, B. et al. An infant with meningitis and unexplained coagulopathy/commentary. Clinical Pediatrics, v. 4I, n. 8, p. 625-7, 2002

13. SPADA, M. La tirosinemia epatorenale. Boll Soc Ital Gatroenterol Epatol Pediatr, v. II, n. 3, p. 9-12, 2003.

I 4.TRINDER, D. et al. Molecular pathogenesis of iron overload. Gut, v. 5 I, n. 2, p. 290-6, 2002.

15.WHITTINGTON, C.A. et al. Review article: haemochromatosis. Aliment Pharmacol Ther, v. 16, p. 1963-75, 2002. 